\title{
Epidemiological and chronological profile of preterm birth in the region of Monastir (Tunisia) between 1994 and 2012
}

\author{
S. ElMhamdi, ${ }^{7}$ M. El Ghardallou, ${ }^{1}$ A. Ben Salah, ${ }^{7}$ I. Bouanene, ${ }^{1}$ A. Sriha, ${ }^{1}$ K. Ben Salem, ${ }^{7}$ R. Falah ${ }^{2}$ and M.S. Soltani ${ }^{1}$
}

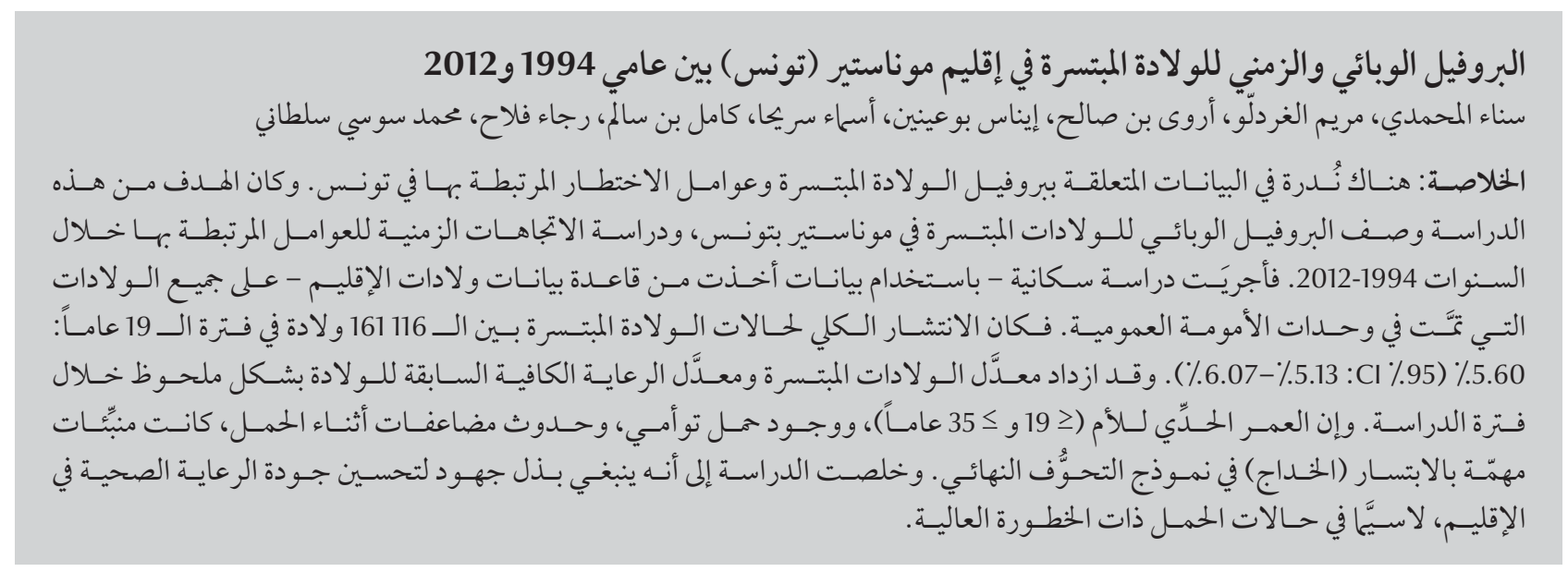

ABSTRACT Data about the profile and risk factors of premature births in Tunisia are scarce. The objective of this study was to describe the epidemiological profile of preterm births in Monastir, Tunisia, and to study the chronological trends of associated factors over the years 1994-2012. A population-based study was conducted using data from the regional births database on all deliveries in public maternity units. The overall prevalence of preterm births among the 161116 deliveries in the 19 -year period was 5.60\% (95\% Cl: 5.13\%-6.07\%). The rate of preterm births and of adequate prenatal care increased significantly over the study period. Extremes of maternal age ( $\leq 19$ and $\geq 35$ years), having a twin pregnancy and the occurrence of complications during pregnancy were significant predictors of prematurity in the final regression model. Efforts should be made to improve the quality of health care in the region, especially for high-risk pregnancies.

Caractéristiques épidémiologiques et chronologiques des naissances prématurées dans la région de Monastir (Tunisie) entre 1994 et 2012

RÉSUMÉ Les données sur les caractéristiques des naissances prématurées et leurs facteurs de risque sont rares en Tunisie. La présente étude avait pour objectif de décrire les caractéristiques épidémiologiques des naissances prématurées à Monastir (Tunisie), et d'étudier les tendances chronologiques des facteurs associés entre 1994 et 2012. Une étude en population a été menée à l'aide de données issues de la base de données des naissances régionale incluant tous les accouchements ayant eu lieu dans des maternités publiques. La prévalence globale des naissances prématurées pour 161116 accouchements sur cette période de 19 ans était de 5,60 \% (IC à $95 \%$ : 5,13\%-6,07\%). Le taux de naissances prématurées et de soins prénatals adéquats a augmenté de manière significative au cours de la période de l'étude. L'âge extrême de la mère ( $\leq 19$ ans ou $\geq 35$ ans), une grossesse gémellaire et la survenue de complications pendant la grossesse étaient des facteurs prédictifs importants de prématurité dans le modèle de régression final. Des actions devraient être menées pour améliorer la qualité des soins de santé dans la région, notamment pour les grossesses à haut risque.

${ }^{2}$ Department of Preventive Medicine and Epidemiology; ${ }^{2}$ Department of Gynaecology and Obstetrics, University Hospital of Monastir, Monastir, Tunisia (Correspondence to S. El Mhamdi: sanaelmhamdi@yahoo.fr).

Received: 16/04/14; accepted: 02/10/14 


\section{Introduction}

Preterm labour - defined as delivery occurring before 37 weeks of gestation (259 days) — is a major determinant of neonatal mortality and has longterm adverse health outcomes (1-4). Compared with term infants, preterm infants have higher rates of cerebral palsy, mental retardation, sensory impairments, dysfunction in cognitive areas (e.g. attention, visual processing, academic progress) and respiratory illnesses in later life $(5,6)$. Causal variables include medical conditions of the mother and of the fetus, environmental exposure and socioeconomic and cultural factors (1).

In developed countries the rate of prematurity ranges from $5 \%$ to $7 \%$ of live births. However, these rates are estimated to be substantially higher in developing countries (1). In Tunisia, despite the activities of the national perinatology programme, data about the profile and risk factors of premature births are scarce (7). The aim of this study was to describe the epidemiological profile of preterm births in the region of Monastir and to study the chronological trends of associated factors over a period of 19 years (1994-2012).

\section{Methods}

\section{Study design and sample}

A retrospective population study was conducted using data from the period January 1994 to December 2012 concerning births at the public maternity facilities of the region of Monastir. According to data from the Moroccan National Statistics Institute, the governorate of Monastir in 2013 had a population of 542100 inhabitants (8). Women of childbearing age (15-49 years) accounted for about $28 \%$ of this population. The study included all newborns aged from 24 to 43 gestation weeks.

\section{Data collection}

Data for this study were collected from the births register which was established by the Department of Preventive Medicine and Epidemiology at the University Hospital of Monastir. This register was implemented in 1990 and all deliveries that occur in the different public health facilities of the region are recorded in the database. The facilities include a university maternity unit (tertiary-care level), 2 regional ones (secondary-care level) and 7 peripheral maternity units (primary-care level).

Midwives in each maternity unit record information in the register about: woman's obstetric history (maternal age, parity, interpregnancy interval, pregnancy complications); current pregnancy and prenatal care (gestational age, twin pregnancies, prenatal visits); and newborn characteristics (prematurity, weight, malformations). To avoid missing data, midwives receive periodic training on the quality of data collection. Members of the Department of Preventive Medicine and Epidemiology make regular visits to maternity units to supervise midwives and ensure the quality of data collection.

\section{Definitions}

For this study preterm delivery was defined as birth before 37 weeks gestational age (259 days of gestation). Gestational age was estimated based on the last menstrual period and/or ultrasound assessment prior to 12 weeks of pregnancy. We considered the age of viability to be 24 weeks $(7,8)$. Preterm births were also subdivided according to gestational age (9) into: extreme prematurity $(<28$ weeks); severe prematurity (28-31 weeks); moderate prematurity (32-33 weeks); and near term (34-36 weeks).

Low birthweight was defined as a birthweight of $<2.5 \mathrm{~kg}(10)$. Pregnancy complications, especially those following complications that require special care, were premature rupture of membranes and eclampsia. Newborn malformations were visible newborn malformations detected during delivery.

Advanced maternal age was defined as age $\geq 35$ years at delivery (11); young maternal age was defined as age $\leq 19$ years at delivery (12). Prenatal care was considered as adequate if the minimum of number of antenatal visits was 4 and the 7 quality criteria were fulfilled $(13,14)$. We defined interpregnancy interval as the interval from the first birth until the estimated date of the last menstrual period before the second pregnancy, expressed in completed months (15). Parity was the number of pregnancies carried to 28 weeks (16) and multiparity was defined as parity $>$ 4 (17).

\section{Data analysis}

Statistical analyses were performed using SPSS, version 17.0. Univariate analyses were used to identify factors associated with preterm delivery. The chi-squared test was used to assess significance for categorical variables. The risks of preterm birth were expressed as odds ratio (OR) with $95 \%$ confidence intervals $(\mathrm{CI})$. A $P$-value $\leq$ 0.05 was considered to be statistically significant.

Multivariate stepwise logistic regression was performed to identify the determinants of preterm birth. In this model, variables with a univariate test value $\leq 0.25$ were included. The final returned variables were those significant at the level of 5\%. To describe the chronological profile, we used the Spearman $(r)$ correlation test.

\section{Results}

\section{Prevalence of preterm births}

Data were analysed from 161116 deliveries in the public maternity facilities of Monastir over the study period 1994-2012. Over the 19year period, the overall prevalence of 
preterm births was 5.60\% (95\% CI: $5.13 \%-6.07 \%$ ) (9023 deliveries) with $1.6 \%$ of deliveries occurring prior to 33 weeks. The distribution of overall deliveries included in the study according to gestational age is presented in Table 1.

The preterm birth rate increased significantly from $4.8 \%$ in 1994 to $7.2 \%$ in $2012(P<0.001)$ (Figure 1). However, the proportion of births from pregnancies with short interpregnancy interval decreased significantly from $30.7 \%$ in 1994 to $21.6 \%$ in $2012(P<0.001)$ (Figure 2). Similarly, the proportion of births in women with adequate prenatal care increased significantly from 50.2\% in 1994 to $79.8 \%$ in $2012(P<0.001)$ (Figure 3).

\section{Characteristics of preterm birth}

The mean maternal age of preterm babies was 28.9 (SD 5.5) years and 17.5\% of women had an advanced age $(\geq 35$ years) age. The mean parity was 2.4 (SD 1.5 ) and $32.3 \%$ of women were primiparas. Almost all the women (96.5\%) had made at least 1 prenatal visit and $66.7 \%$ on average had received adequate prenatal care.

Among preterm deliveries, 6776 (75.1\%) were vaginal deliveries and 2247 (24.9\%) were caesarean section deliveries; 4692 preterm infants (52.0\%) had a low birth weight $(<2.5$ $\mathrm{kg})$.

The results of the univariate analyses of factors associated with preterm birth are displayed in Table 2 . Maternal factors significantly associated with increased risk of preterm birth were: extremes of maternal age ( $\leq 19$ or $\geq 35$ years); primiparity or multiparity; and short interpregnancy interval (<24 months). Women with inadequate prenatal care were more exposed to the risk of preterm delivery (crude OR 1.19; 95\% CI: 1.06-1.17). A male fetus was also at higher risk of preterm birth (ORc 1.07; 95\% CI: $1.02-1.13)$. Mothers who had a

\begin{tabular}{lcc}
\hline $\begin{array}{l}\text { Table 1 Distribution of deliveries in the Monastir region of Tunisia according to } \\
\text { infant's gestational age, 1994-2012 }\end{array}$ & No. \\
\hline Variable & 644 & 0.4 \\
Extreme prematurity (<28 weeks) & 806 & 0.5 \\
Severe prematurity (29-31 weeks) & 1128 & 0.7 \\
Moderate prematurity (32-33 weeks) & 6445 & 4.0 \\
Near term (34-36 weeks) & 152093 & 94.4 \\
Term & 161116 & 100.0 \\
\hline Total &
\end{tabular}

twin pregnancy were more likely to have earlier labour (ORc 12.43; 95\% CI: 11.1-14.0). ). Data on newborn malformations and pregnancy complications identified from the register were also significantly associated with preterm birth.

\section{Regression analysis of risk factors for premature birth}

Table 3 shows that the risk factors for premature birth in the final regression model were extremes of maternal ages $(P<0.001)$; twin pregnancy (adjusted OR 2.12; 95\% CI: 1.45-3.10); and

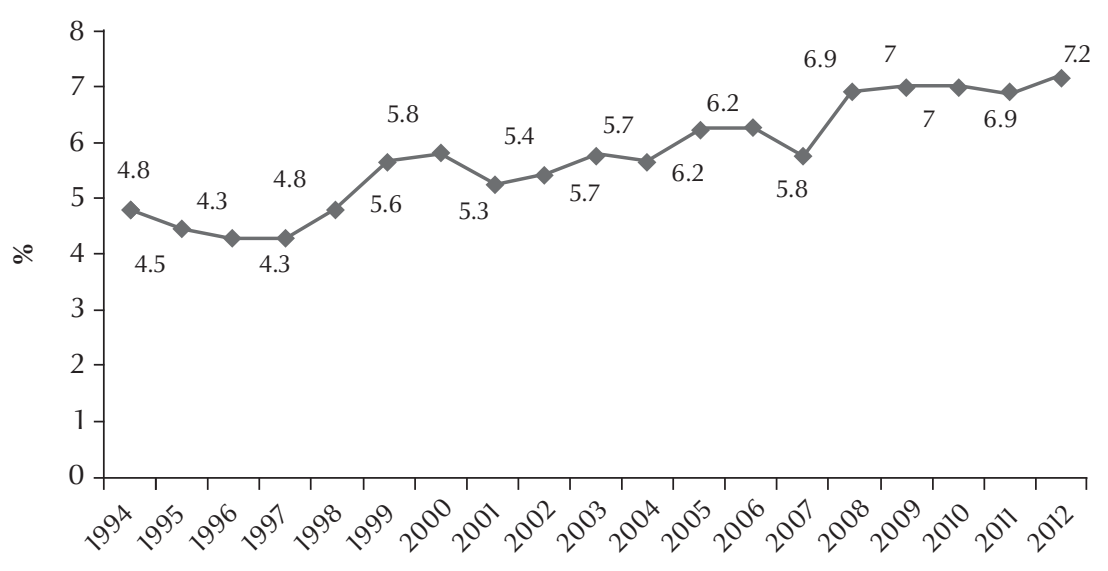

Figure 1 Trends of premature births in the region of Monastir, Tunisia, 1994-2012

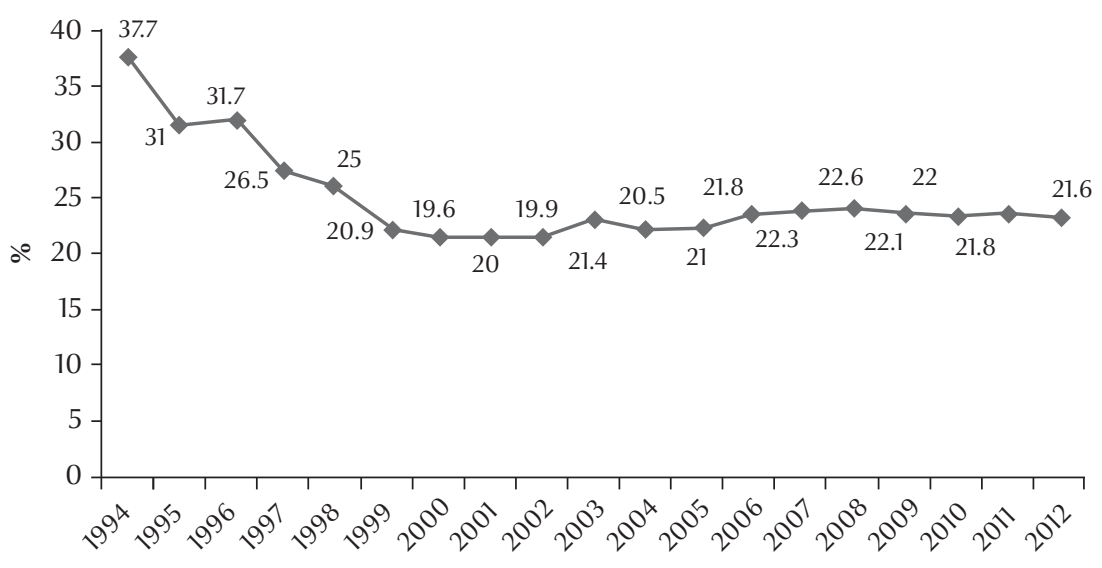

Figure 2 Trends of births in which mother had short interpregnancy interval $(<24$ months) in the region of Monastir, Tunisia, 1994-2012 


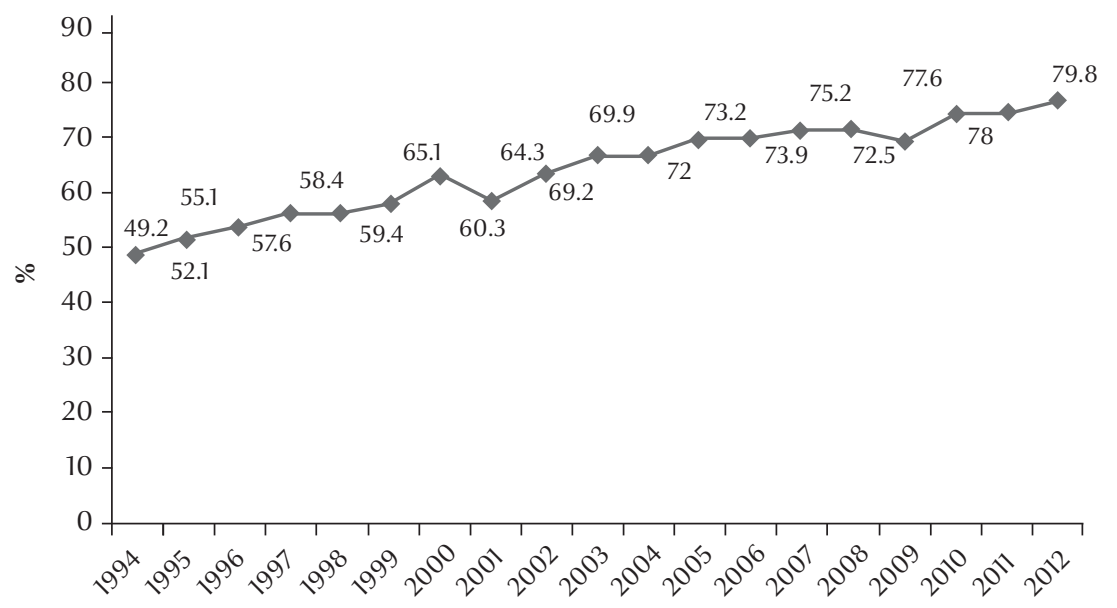

Figure 3 Trends of births in which mother received adequate prenatal care (minimum 4 antenatal visits plus 7 quality criteria met) in the region of Monastir, Tunisia, 1994-2012

occurrence of complications during pregnancy (ORa 1.85; 95\% CI: $1.74-$ 1.96).

\section{Discussion}

This study aimed to provide an estimate of the preterm birth rate in the region of Monastir in Tunisia. We also identified the determinants of preterm births and their trends in the region over a period of 19 years. The data were derived from the births register of the Department of Preventive Medicine and Epidemiology at the University Hospital of Monastir. The database had a number of benefits, as it provided data for this population study without the selection bias of hospital studies. It also had some limitations, such as collecting data only on deliveries in public sector facilities and the lack of data on subsequent pregnancies. However, the proportion of deliveries outside the public sector are less than $10 \%$ for private clinics and less than $1 \%$ for home-birth deliveries in the region $(18,19)$. Although we used a large database our results cannot be extrapolated to the whole country. They may be used as guidance for our country and for other North African populations with the same ethnic origin (Arab Berber) and cultural features. Another limitation of the database was the lack of data on the women's socioeconomic and behavioural factors (smoking, alcohol, drug abuse) and these are also factors that may influence the risk of premature births.

According to the World Health Organization, preterm birth is a major determinant of neonatal mortality and morbidity and has long-term adverse consequences for health (20). It represents one of the most significant problems in perinatology and is of concern in both developed and developing countries. Preterm birth rates have been reported to range from $5 \%$ to $7 \%$ of live births in some developed communities but are estimated to be substantially higher in developing countries $(1,21)$. The prevalence of preterm birth varies widely by country all over the world. In this study, the prematurity rate was estimated at $5.60 \%$. This result in one region of Tunisia is lower in comparison with other north African countries; for example, $8 \%$ in Morocco and $6.7 \%$ in Libya $(22,23)$.

Preterm birth rates, as an indicator of maternal and perinatal health, reflect health disparities between regions. In Tunisia, the preterm birth rate increased significantly from 1994 to 2012. This increase could be explained by the great changes that have taken place in the lifestyles of Tunisian women over this period (such as working outside the home and marriage at older ages), but also to improvements in the quality of prenatal care and the success of national prevention programmes (such as screening for fetal and maternal conditions requiring early induction of delivery) (16). Indeed, during the last decade, we noticed that the rate of adequate prenatal care also increased. As a result, risk factors for prematurity are being identified earlier. This trend was also highlighted in high-income countries such the United States of America and Japan. According to the vital statistics of Japan, the preterm birth rate has increased significantly from $4.1 \%$ in 1980 to $5.8 \%$ in 2007. This finding was explained differently and improvements in reproductive health technology were believed to be the major contributor to this trend (24).

The determinants for preterm delivery in our population that were identified in univariate analysis were twin pregnancy, extremes of maternal age, interpregnancy interval, sex of newborn and newborn malformations. Twin pregnancy remained significantly associated with preterm delivery even after adjustment in the multivariate model. In fact, according to international statistics, nearly $60 \%$ of twins are preterm births and about $40 \%$ of twin births will lead to spontaneous labour before 37 weeks of gestation (3). This observation underlines the importance of follow up for high-risk, multiple-gestation pregnancies.

Extremes of maternal age $(\leq 19$ years and $\geq 35$ years) were also identified as risk factors of prematurity in the final model, a finding which is in concordance with several other studies (25-27). Silveira et al., using the data of a birth cohort study which included all hospitals births in Pelotas, Brazil, found that young maternal age was an important risk factor, probably due to biological immaturity of the mother 


\begin{tabular}{|c|c|c|c|c|c|c|}
\hline \multirow[t]{2}{*}{ Variable } & \multirow{2}{*}{$\begin{array}{l}\text { Total } \\
\text { No. }\end{array}$} & \multicolumn{2}{|c|}{ Preterm births } & \multirow[t]{2}{*}{ Crude OR } & \multirow[t]{2}{*}{$95 \% \mathrm{Cl}$} & \multirow[t]{2}{*}{$P$-value } \\
\hline & & No. & $\%$ & & & \\
\hline Maternal age (years) & & & & & & $<0.001$ \\
\hline 20-34 & 129460 & 7188 & 79.7 & 1 & & \\
\hline$\leq 19$ & 3413 & 256 & 2.8 & 1.24 & $1.17-1.54$ & \\
\hline$\geq 35$ & 28243 & 1579 & 17.5 & 1.78 & $1.17-1.98$ & \\
\hline Parity & & & & & & $<0.001$ \\
\hline $2-3$ & 75878 & 4284 & 47.5 & 1 & & \\
\hline 1 & 52223 & 2914 & 32.3 & 1.29 & $1.23-1.35$ & \\
\hline$>3$ & 33015 & 1825 & 20.2 & 3.48 & $1.33-8.63$ & \\
\hline Interpregnancy interval (months) & & & & & & 0.003 \\
\hline$\geq 24$ & 123483 & 6731 & 74.6 & 1 & & \\
\hline$<24$ & 37512 & 2292 & 25.4 & 1.12 & $1.03-1.21$ & \\
\hline Prenatal care & & & & & & $<0.001$ \\
\hline Adequate & 105949 & 5775 & 64 & 1 & & \\
\hline Inadequate & 55068 & 3248 & 36 & 1.10 & $1.06-1.16$ & \\
\hline Sex & & & & & & 0.04 \\
\hline Female & 78786 & 4232 & 46.9 & 1 & & \\
\hline Male & 82330 & 4791 & 53.1 & 1.07 & $1.03-1.13$ & \\
\hline Twin pregnancy & & & & & & $<0.001$ \\
\hline No & 143900 & 7453 & 82.6 & 1 & & \\
\hline Yes & 17216 & 1570 & 17.4 & 1.68 & $1.59-1.78$ & \\
\hline Malformations & & & & & & $<0.001$ \\
\hline No & 160882 & 8930 & 98.9 & 1 & & \\
\hline Yes & 234 & 93 & 1.1 & 2.17 & $1.49-3.16$ & \\
\hline Complications & & & & & & $<0.001$ \\
\hline No & 160819 & 8992 & 99.6 & 1 & & \\
\hline Yes & 297 & 31 & 0.4 & 2.3 & $1.58-3.34$ & \\
\hline Birthweight & & & & & & $<0.001$ \\
\hline Normal weight & 133243 & 4136 & 45.8 & 1 & & \\
\hline Low birth weight & 19334 & 4692 & 52 & 3.46 & $2.88-4.17$ & \\
\hline Macrosomia & 8539 & 195 & 2.2 & 1.76 & $0.61-2.92$ & \\
\hline Type of delivery & & & & & & $<0.001$ \\
\hline Vaginal delivery & 137593 & 6588 & 73 & 1 & & \\
\hline Forceps delivery & 4189 & 152 & 1.7 & 3.49 & $1.58-4.57$ & \\
\hline Caesarean section & 19334 & 2283 & 25.3 & 9.19 & $7.55-10.9$ & \\
\hline
\end{tabular}

$O R=$ odds ratio; $C I=$ confidence interval.

(25). Delbeare et al., using data obtained from a regional populationbased perinatal database in Brussels, reported that older maternal age was an independent risk factor for adverse pregnancy outcomes including very preterm birth (26).

According to the literature, women with a short interpregnancy interval are at increased risk of preterm delivery
(28). During the study period the proportion of pregnancies with short interpregnancy interval decreased, presumably as a consequence of the high educational level of Tunisian women and the promotion of contraception use as part of family planning strategies. However, interpregnancy interval was not identified as a determinant of preterm birth.
Giving birth to a male fetus was associated with preterm birth in the univariate analysis but not in the multiple regression analysis. Lao et al. has confirmed this result in their study of Chinese women with singleton pregnancies and concluded that carrying a male fetus is an independent risk factor for spontaneous preterm labour and preterm birth at 34-36 weeks of gestation (29). 


\begin{tabular}{|c|c|c|c|}
\hline \multicolumn{4}{|c|}{$\begin{array}{l}\text { Table } 3 \text { Factors associated with prematurity: results of the multivariate logistic } \\
\text { regression analysis }\end{array}$} \\
\hline Variables & Adjusted OR & $95 \% \mathrm{CI}$ & $P$-value \\
\hline Twin pregnancy & & & $<0.001$ \\
\hline No & 1 & & \\
\hline Yes & 2.12 & $1.45-3.10$ & \\
\hline Maternal age (years) & & & $<0.001$ \\
\hline $20-34$ & 1 & & \\
\hline$\leq 19$ & 1.28 & $1.21-1.36$ & \\
\hline$\geq 35$ & 1.32 & $1.14-1.52$ & \\
\hline Complications & & & $<0.001$ \\
\hline No & 1 & & \\
\hline Yes & 1.85 & $1.74-1.96$ & \\
\hline
\end{tabular}

$O R=$ odds ratio $; C l=$ confidence interval.

A higher risk of preterm birth among newborns with congenital anomalies was observed in the crude analyses, but was no longer significant after adjustment for other factors. In fact, previous studies reported that infants with congenital anomalies such as neural-tube defects are more likely to be delivered preterm (3).

In our study, maternal complications during labour (premature rupture of membranes and eclampsia) were identified as determinants of preterm delivery. This result was found in other studies that reported higher rate of pregnancy complications in women with preterm births (30).

A relationship between prenatal care and prematurity risk has been identified in the literature $(31,32)$. An American study found that women without prenatal care faced up to a 7 times greater risk of preterm birth compared with those attending $75 \%$ to $100 \%$ of recommended visits (29). However, other studies doubted the effectiveness of prenatal care for preventing prematurity (24). In our study, we noticed a significant increase of the proportion of women receiving adequate prenatal care over the 19-year study period, which probably reflects improved knowledge about and interest in prenatal care among pregnant women.

\section{Conclusions}

Early induced deliveries may be unavoidable for some conditions. However, the results of our study show that we need to enhance the management of multiple pregnancies and pregnancies at the extremes of maternal ages to reduce the rate of spontaneous prematurity in this region.

Competing interests: None declared.

\section{References}

1. Beck S, Wojdyla D, Say L, Betran AP, Merialdi M, Requejo JH, et al. The worldwide incidence of preterm birth: a systematic review of maternal mortality and morbidity. Bull World Health Organ. 2010 Jan;88(1):31-8. PMID:20428351

2. Nguyen N, Savitz DA, Throp JM. Risk factors for preterm birth in Vietnam. Int J Gynaecol Obstet. 2004 Jul;86(1):70-8. PMID: 15207686

3. Goldenberg RL, Culhane JF, lams JD, Romero R. Epidemiology and causes of preterm birth. Lancet. 2008 Jan 5;371(9606):7584. PMID:18177778

4. Nouaili EB, Chaouachi S, Ayadi I, Ben Said A, Zouari B, Marrakchi $Z$. Risk factors for perinatal mortality in a Tunisian population. Int J Gynaecol Obstet. 2010 Dec;111(3):265-6. 10.10 PMID:20817177

5. Saigal S, Doyle LW. An overview of mortality and sequelae of preterm birth from infancy to adulthood. Lancet. 2008 Jan 19;371(9608):261-9. PMID:18207020

6. Mura T, Picaud JC, Larroque B, Galtier F, Marret S, Roze JC, et al.; Etude Epidémiologique sur les Petits Ages Gestationnels (EPIPAGE) Study Group. Cognitive impairment at age 5 years in very preterm infants born following premature rupture of membranes. J Pediatr. 2013 Aug;163(2):435-40. 10.1016/j. jpeds.2013.01.039 PMID:23490036

7. Amri F, Fatnassi R, Negra S, Khammari S. Prise en charge du nouveau-né. [Management of premature neonates.] J Pediatr Pueric. 2008;21:227-31.

8. Données démographiques et sociales: Répartition de la population par gouvernorat. Les indicateurs les plus recents [Inter- net]. Tunis, Tunisie: Institut National de la Statistique (http:// www.ins.nat.tn/indexfr.php, accessed 3 November 2014).

9. Rossi P, Tauzin L, Grosse C, Simeoni U, Frances Y. Impact de l'age gestationnel et du poids de naissance sur le devenir cardiovasculaire a long terme. [Impact of gestational age and birthweight on long-term cardiovascular health]. Rev Med Interne. 2007 Aug;28(8):545-51. PMID:17482724

10. Tucker J, McGuire W. ABC of preterm birth: epidemiology of preterm birth. BMJ. Sep 18, 2004; 329(7467):675-8. PMID:15374920

11. Kale A, Kuyumcuoğlu U, Güzel A. Is pregnancy over 45 with very high parity related with adverse maternal and fetal outcomes? Clin Exp Obstet Gynecol. 2009;36(2):120-2. PMID:19688957

12. Karabulut A, Ozkan S, Bozkurt Al, Karahan T, Kayan S. Perinatal outcomes and risk factors in adolescent and advanced age pregnancies: comparison with normal reproductive age women. J Obstet Gynaecol. 2013 May;33(4):346-50. PMID:23654312

13. El Mhamdi S, Soltani MS, Haddad A, Letaief M, Ben Salem K. Les nouveaux critères et la qualité des services de soins de santé dans le gouvernorat de Monastir (Tunisie). [New criteria and quality of health care services in the governorate of $\mathrm{Mo}$ nastir, Tunisia]. East Mediterr Health J. 2010 Jan;16(1):107-12. PMID:20214167

14. Antenatal care in developing countries. Promises, achievements and missed opportunities: an analysis of trends, levels and differentials, 1990-2001. Geneva: World Health 
Organization; 2003 (http://whqlibdoc.who.int/publications/2003/9241590947.pdf, accessed 27 November 2014).

15. Smith GCS, Pell JP, Dobbie R. Interpregnancy interval and risk of preterm birth and neonatal death: retrospective cohort study. BMJ. 2003 Aug 9;327(7410):313. PMID:12907483

16. El Mhamdi S, Lifi B, Bouanène I, Hadded A, Sriha A, Letaief M, et al. Caracteristiques epidemiologiques et chronologiques du faible poids de naissance dans la region de monastir (Tunisie) entre 1994 et 2007. [Epidemiological and chronological profile of the low birth weight in the region of Monastir (Tunisia) between 1994 and 2007]. Rev Med Brux. 2011 MayJun;32(3):147-53. PMID:21834443

17. Al JF. Grandmultiparity: a potential risk factor for adverse pregnancy outcomes. J Reprod Med. 2012 Jan-Feb;57(1-2):53-7. PMID:22324269

18. Ratzon R, Sheiner E, Shoham-Vardi I. The role of prenatal care in recurrent preterm birth. Eur J Obstet Gynecol Reprod Biol. 2011 Jan;154(1):40-4. PMID:20869804

19. Bchir A, Bouchahda $M$, Soltani $M$, Riahi M, Jebra H. Le registre des naissances: outil d'évaluation des activités de santé maternelle et infantile à l'échelle du district. [The birth register as an evaluation tool of maternal and child health activities at district level.] East Mediterr Health J. 1996;2:418-24.

20. Born too soon: the global action report on preterm birth. Geneva: World Health Organization; 2012 (http://apps.who.int/ iris/bitstream/10665/44864/1/9789241503433_eng.pdf?ua=1, accessed 27 November 2014).

21. Enquête sur la santé et le bien-être de la mère et de l'enfant (Multiple Indicator Cluster Survey). Tunis, Tunisie: Ministère de la Santé Publique, Office National de la Famille et de l'Enfant et UNICEF; 2008.

22. Barakat A, Mdaghri Alaoui A, Hamdani S, Lamdouar Bouazaoui $\mathrm{N}$. Problématique de la prise en charge de la prématurité au Maroc. Expérience du service de Néonatologie Centre Nan tional de Référence en Néonatologie, Hôpital d'Enfants. Rabat, Maroc: Jeunes du Maroc; 2004. p. 4.

23. Khalil MM, Alzahra E. Fetal gender and pregnancy outcomes in Libya: a retrospective study. Libyan J Med. 2013;8. doi: 10.3402/ljm.v8i0.20008. PMID:23308081
24. Takayama JI, Matsuo N. The enigma of spontaneous preterm birth. N Engl J Med. 2010 May 27;362(21):2032-3. PMID:20518106

25. Silveira MF, Victora CG, Barros AJD, Santos IS, Matijasevich A, Barros FC. Determinantes de nascimento pré-termo na coorte de nascimentos de 2004, Pelotas, Rio Grande do Sul, Brasil. [Determinants of preterm birth: Pelotas Rio Grande do Sul State, Brazil, 2004 birth cohort.] Cad Saúde Pública. 2010;26:185-94.

26. Delbaere I, Verstraelen H, Goetgeluk S, Martens G, De Backer G, Temmerman M. Pregnancy outcome in primiparae of advanced maternal age. Eur J Obstet Gynecol Reprod Biol. 2007 Nov;135(1):41-6. PMID:17118520

27. Shrim A, Ates S, Mallozzi A, Brown R, Ponette V, Levin I, et al. Is young maternal age really a risk factor for adverse pregnancy outcome in a Canadian tertiary referral hospital? J Pediatr Adolesc Gynecol. 2011 Aug;24(4):218-22. PMID:21620742

28. Smith GC, Pell JP, Dobbie R. Interpregnancy interval and risk of preterm birth and neonatal death: retrospective cohort study. BMJ. 2003 Aug 9;327(7410):313. PMID:12907483

29. Lao TT, Sahota DS, Suen SS, Law LW. The impact of fetal gender on preterm birth in a southern Chinese population. J Matern Fetal Neonatal Med. 2011 Dec;24(12):1440-3. PMID:22023147

30. Boivin A1, Luo ZC, Audibert F, Mâsse B, Lefebvre F, Tessier R, et al. Pregnancy complications among women born preterm. CMAJ. 2012 Nov 6;184(16):1777-84. PMID:23008489

31. Debiec KE, Paul KJ, Mitchell CM, Hitti JE. Inadequate prenatal care and risk of preterm delivery among adolescents: a retrospective study over 10 years. Am J Obstet Gynecol. 2010;203:122.e1-6. PMID:20471628

32. Shrestha S, Dangol SS, Shrestha M, Shrestha RP. Outcome of preterm babies and associated risk factors in a hospital. JNMA J Nepal Med Assoc. 2010 Oct-Dec;50(180):286-90. PMID:22049892 